\title{
Yenilenebilir Kaynakların Mürekkep Üretiminde Kullanılabilirliğinin İncelenmesi
}

\author{
Pelin HAYTA ${ }^{1} \mathscr{\&}$, Mehmet OKTAV ${ }^{2}$ \\ ${ }^{1}$ Tasarım Bölümü, Gerze Meslek Yüksekokulu, Sinop Üniversitesi, Sinop, Türkiye \\ ${ }^{2}$ Basım Teknolojileri Bölümü, Uygulamalı Bilimler Yüksekokulu, Marmara Üniversitesi, İstanbul, Türkiye \\ $\bowtie$ : pelin@ hayta.com.tr, (iD) 10000-0003-1613-0785, (iD)20000-0002-9872-4802
}

Geliş (Received): 02.10.2020

Düzeltme (Revision):13.11.2020

Kabul (Accepted): 23.11.2020

\begin{abstract}
ÖZ
Basım sektöründe mürekkep temel hammaddelerden birisi olarak yer almaktadır ve yapısında petrokimyasal maddeler de bulunmaktadır. Mürekkebin yapısında yer alan petrokimyasal maddeler mürekkepten ayrıldığında insan sağlığı ve çevre için tehlikeli olabilmektedir. Özellikle baskı esnasında havaya karışan uçucu organik bileşiklere fazla maruz kalındığında meslek hastalıklarına neden olmaktadır. Petrokimyasal maddelerin çevreye ve insan sağlığına verdiği zararlar tüm dünyada yenilenebilir kaynakların araştırılmasını gereklilik haline getirmiştir. $\mathrm{Bu}$ doğrultuda basım endüstrisinde yenilebilir kaynakların kullanımına ilişkin yapılan çalışmalar önem arz etmektedir. $\mathrm{Bu}$ incelemenin amacı; mürekkep bileşeninde yenilenebilir kaynakların kullanılabilirliğine ilişkin yapılan araştırmaları ve sonuçlarını irdeleyerek basım sektörüne bilgi sağlamak ve teşvik etmektir. Bu amaçla ulusal ve uluslararası çalışmalar araştırılmış, gerekli literatür taramaları yapılarak irdelenmiş ve araştırma sonuçlarının basılabilirlik etkileri ortaya konulmuştur.
\end{abstract}

Anahtar Kelimeler: Basılabilirlik, Baskı Mürekkebi, VOC, Yenilenebilir Kaynak

\section{Examination the Availability of Renewable Resources in Ink Production}

\begin{abstract}
Ink is one of the basic raw materials in the printing industry and it contains petrochemicals. When petrochemical substances in the ink structure are separated from the ink, it can be dangerous for human health and the environment. Especially when exposed to volatile organic compounds that are released into the air during printing, it causes occupational diseases. The damage caused by petrochemicals to the environment and human health has made it necessary to research renewable resources all over the world. In this direction, studies on the use of renewable resources in the printing industry are important. The purpose of this review is; to provide information for printing industry by examining the researches and results of the renewable resources in ink component and encourage this industry. For this purpose, national and international studies were researched, the necessary literature reviews were made and the printability effects of the research results were explained.
\end{abstract}

Keywords: Printability, Printing Ink, Renewable Resources, VOC

\section{GiRiş}

Mürekkep basım sektöründe kullanılan temel hammaddelerden birisidir. Geçmişten günümüze baskı işlemini geçekleştirebilmek amacıyla her bir baskı tekniğine uygun olarak mürekkep üretilmiștir. Gutenberg 1440 yılında tipo baskida; hurufatları kullanabilmek için keten tohumu ve ceviz yağı gibi farklı bitkisel yağları kaynatarak yağ temelli mürekkebi üretmiştir [1]. Endüstriyel anlamda tarihte bilenen ilk matbaa mürekkebi üretimi 1818 yllında Fransız matbaacısı Pierre Lorilleux'in ilk mürekkep fabrikasını kurması ve yaptığ 1 mürekkepleri diğer matbaalara satmasıyla başlamıştır [2]. Zamanla değişen petrol ve türevlerinden elde edilen petrokimyasal maddeler mürekkeplerden istenilen özelliklerin elde edilebilmesi amacıyla mürekkep formülasyonuna dahil edilmiştir. Baskı mürekkeplerinin içindeki mürekkep yağları ve çözücüler, baskı işlemi esnasında atılabilen uçucu organik bileşiklerdir [3]. Mürekkep endüstrisinde VOC'lar (uçucu bir organik bileşikler), "buharlaşma oranı ne kadar sürerse sürsün sonunda mürekkepten buharlaşacak" bir mürekkepteki herhangi bir organik malzeme olarak tanımlanır [4]. Özellikle oda sıcaklığında kolayca buharlaşabilen kimyasallar olan VOC'ların (uçucu organik bileşiklerin) hemen hemen hepsi bir miktar toksisiteye sahiptir [5]. VOC'ların çoğu toksiktir ve insan sağlığı için tehlikeli kabul edilir [6-8]. Hava kalitesini bozan canlı ve cansız çevre için olumsuz etkileri olan VOC'ların ölçülmesi ve belirlenmiş sınır değerlerin altına indirilmesi gerekmektedir [9]. Amerika'da 1990 tarihli Temiz Hava Yasası (Clean Air Act) Değişiklikleri uyarınca, VOC'nin birçok ayrı bileşeni tehlikeli hava kirleticileri (HAP'ler) olarak tanımlanmıştır ve bu nedenle kontrol gerektirir [10-12]. VOC emisyonu, nitrojen oksitleri, diğer kirleticiler ve güneş 1şı̆̆ 1 ile reaksiyona girerek fotokimyasal duman (ozon) oluşumuna yol açar. Fotokimyasal duman insan sağlığını etkiler [13]. Mürekkeplerin çoğunda bulunan petrokimyasal maddeler insan sağlığını ve çevreyi olumsuz yönde etkilemektedir. 
Baskı çözücülerinin çevresel emisyonları, zemin seviyesinde ozon oluşumuna neden olabilir ve bazıları stratosferdeki ozon tabakasının incelmesine katkıda bulunabilir [14]. Ayrıca kaynak tüketimindeki ve atık oluşumundaki büyük artış nedeniyle sürdürülemez üretim sistemleri yaşanılan çevresel zorluklardandır [15, $16]$.

Günümüzde, uçucu organik bileşiklerin emisyonuna ilişkin kaygılar, daha çevre dostu ürünler üretmek için sanayi malzemelerinin tabanı olarak solventlerin azaltılmasına veya ortadan kaldırılmasına yol açmaktadır [17-19]. Bu kapsamda petrokimyasal maddelerin zararını ortadan kaldırmak ve 1970'lerde dünyada oluşan petrol krizine alternatif çözümler üretmek amaciyla mürekkep üretiminde araştırmalar yapılmıştır. Amerikan Gazete Yayıncıları Birliği 1970'lerde mürekkep yapmak ve standart petrol mürekkebine bağımlılığı azaltmak için alternatif yollar aramıştır [20]. 1980'lerin başlarında Amerikan Gazete Yayıncıları Birliği (ANPA), "gilsonit" ve yüksek yağlı yağ asitlerinin karbon karası pigmenti ile bir karışımını içeren bir dizi mürekkep formülasyonu geliştirdi. Fakat yüksek yağın maliyeti, bulunabilirliği ve "gilsonit" in neden olduğu ekipman temizliğinin zorluğu, bu mürekkeplerin endüstri tarafindan kabulünü sınırladı $[21,22]$. Bu nedenle bu dönemlerde petrokimyasal maddelere talep artt1. Teknolojideki ilerleme ve gelişmeler sayesinde, günümüzde yağ elde edilen bitkiler büyük miktarlarda yetiştirilmekte ve yağlar kolaylıkla çıkarılıp istenen kalitede rafine edilmektedir [23]. Bitkisel yağların daha kolay elde edilebilmesi ve petrokimyasal ürünlerin verdiği zararlara karşı bitkisel ürünlerin kullanımına ilişkin artan talep yenilenebilir kaynaklara ilişkin araştırmaları arttırmıştır. Özellikle matbaa mürekkebi endüstrisi alanında, mürekkeplerdeki mineral yağın bitkisel yağlar ve türevleri ile değiştirilmesi için son yıllarda bir baskı yaratılmıştır $[24,25]$.

Bitkisel yağların sürekli yenilenebilir olması, petrolden elde edilen ürünlerden daha kolay bozunabilir, çevre üzerindeki etkilerinin daha az olması ve uzun yağlı asit zincirlerinin istenilen esnekliği sağlayabilmesi nedeniyle avantajlı olan bitkisel yağların kullanımına olan eğilim arttırmıştır [26]. Uçucu organik bileşiklerin azaltılarak yenilenebilir kaynaklara dayalı hammaddelerin kullanılmasıyla basılı ürünlerin çevresel etkileri azaltılabilir [27]. Bu kapsamda alternatif yenilenebilir kaynakların araştırılması ve mürekkep gibi temel bir hammaddenin üretimi için kullanılması ekonomik ve ekolojik açıdan önem arz etmektedir. Ayrıca bu alanda yapılan çalışmalar yenilenebilir kaynakların ve atık maddelerin kullanımına ilişkin araştırmalara teşvik sağlamaktadır. $\mathrm{Bu}$ incelemenin amac1; mürekkep bileşeninde yenilenebilir kaynakların kullanılabilirliğine ilişkin yapılan araştırmaları ve sonuçlarını irdeleyerek basım sektörüne bilgi sağlamak ve teşvik etmektir. Bu amaçla ulusal ve uluslararası çalışmalar araştırılmış, gerekli literatür taramaları yapılarak irdelenmiş ve araştırma sonuçlarının basılabilirlik etkileri ortaya konulmuştur.

\section{Mürekkep Ana Bileşenleri}

Baskı mürekkebi, renkli bir pigmentin bir sıvı içindeki dispersiyonudur ve bir baskı altı malzemesi üzerinde görüntü meydana getirmek üzere formüllendirilir [3]. Bütün bask1 mürekkepleri dört ana bileşenden oluşmaktadır; (şekil 1) renklendirici, bağlayıcı, çözücü ve katk1 maddeleri [1, 28]. Mürekkeplerin görsel özellikleri olan rengi, transparanlığg1, örtücülüğü ve parlaklığı renklendiricilerin özelliği ile belirlenir [29]. Mürekkebe renk veren ve çözünürlüklerine göre değerlendirilen renklendiriciler; pigmentler ve boyar maddeler olarak ikiye ayrılırlar [30]. Boyar maddeler, su veya solventte çözünürken pigmentler mürekkep içerisinde çözünmeden dağılan yapıdadırlar. Bağlayıcı maddeler; toz halinde bulunan pigment taneciklerinin sıvı mürekkep içerisinde baskı materyaline aktarılarak ince bir mürekkep filmi oluştururlar. Bunun yanı sıra bağlayıcılar mürekkebin reolojik ve mekanik özelliklerinin belirlenmesi için kullanılırlar [1, 31]. Baskı mürekkebi içerisinde bağlayıcı olarak kullanılan reçineler mürekkebin sertlik, parlaklık, yapışkanlık ve esneklik özelliklerine katkıda bulunurlar [29]. Reçineler doğal ve sentetik olmak üzere iki tipte olurlar. Doğal reçineler bitkisel maddelerden elde edilirler. Sentetik reçineler ise nispeten küçük moleküller arasında yoğunlaşma veya ilave reaksiyonları içeren polimerizasyon ile hazırlanır [29, 32]. Çözücüler bağlayıcı maddeyi çözerek mürekkebin viskozitesini ayarlarlar [1]. Katkı maddeleri ise mürekkebin çeşidine bağlı olarak kuruma, akış hareketi ve aşınma direnci gibi özellikler kazandırması amacıyla mürekkebe eklenirler.

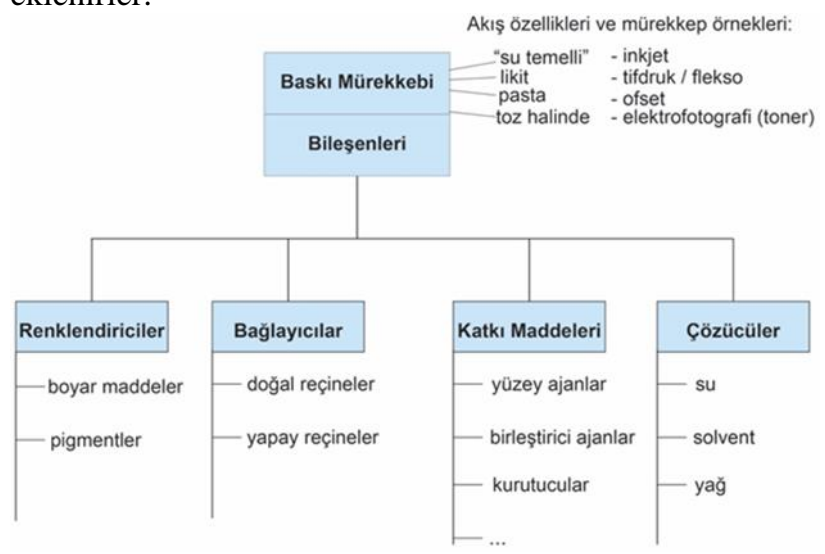

Şekil 1. Bask1 Mürekkeplerinin Bileşimi [33].

Her bir baskı tekniğine bağlı olarak ana bileşenlerin yanı sıra mürekkepten istenilen özelliklerin mürekkebe kazandırılması amacıyla mürekkep içeriğine yardımcı katkı maddeleri eklenmektedir. Böylelikle farklı bask1 tekniklerine ve baskı altı malzemelerine göre farklı tür mürekkepler üretilmektedir.

\section{Mürekkep Bileşeninde Yer Alan Kimyasallar}

Mürekkep imalatında temel bileşenlerinin formüle edilmesinin yanı sıra üretime dahil olan her bileşen mürekkebin yapısında fiziksel ve kimyasal değişime, dolayısıyla baskıdan istenilen özelliklerin de değişimine neden olur. Üretim esnasında mürekkebin bileşenlerinin değişimi kuruma, renk, akma, yapışma özellikleri, 1sı, 
1şık, su ve diğer çevresel faktörler nedeniyle de bozulmaya karşı direnç gibi özelliklerini etkiler (tablo 1). Fakat mürekkebe istenilen özellikleri kazandiran kimyasalların baskı esnasında veya baskı sonrasında mürekkepten ayrılarak havaya, suya ve toprağa karışması doğaya ve insana çeşitli zararlar vererek ekolojik yapının bozulmasında etkili olmaktadır.

Mürekkebin yapısında yer alan inorganik pigmentler, metal oksitler veya metal oksit içeren hammaddelerin yüksek sıcaklıklarda $\left(500-1400^{\circ} \mathrm{C}\right) \quad$ ssıl işlemden geçirilmesiyle üretilirler [34]. Çoğu inorganik pigment, kritik seviyelerin aşılması durumunda çevreyi ve insan sağlığını olumsuz etkileyebilecek ağır metaller veya geçiş metalleri içerir [35]. Mürekkep yapımında yer alan çözücüler aromatik ve alfatik hidrokarbonlar, alkoller (etil ve metil alkol, izopropanol, dietoksi prapanol, glikol, gliserin), ketonlar (aseton, metilisobutilketon, metiletilketon), esterler (etil asetat, n-butil asetat, npropil asetat, isopropil asetat, propilen glikol mono etil eter asetat, propilen glikol mono metil eter asetat), kuruyan yağlar ve mineral yağlar sıklıkla kullanılır [36]. Solvent bazlı mürekkeplerde etanol, etil asetat gibi solvent içerikli çözücüler yanıcı ve parlayıcı maddeler olarak kullanılırken dikkat edilmesi gereken maddelerdir. İzopropanol, mürekkep çözücüleri ve nafta gibi yıkama çözücüleri kolayca tutuşur ve uygun koşullar oluştuğunda patlarlar [5]. Mürekkep bileşeninde yer alan çözücülerin genelinde VOC az veya çok miktarda yer almaktadır. Flekso baskıda yaygın olarak kullanılan su bazlı mürekkepler bile bağlayıcının çözülmesine ve performansın iyileştirilmesine katkıda bulunması için bir miktar uçucu organik madde içerir [3]. Uçucu organik bileşikler, yüksek buhar basıncı, mükemmel yanıcılık ve düşük suda çözünürlük özellikleri ile karakterize edilir. Değişken kimyasal reaktiviteye sahip kimyasal türler olarak, VOC'lerin kontrol edilmesi çok zordur [37]. Atmosfere VOC emisyonlarının kontrolü en büyük çevre sorunlarından biridir [38].

Tablo 1. Mürekkeplerin Kimyasal İçerikleri [30].

\begin{tabular}{llll}
\hline Bileşenler & Su Bazlı & Solvent Bazlı & Yağ Bazlı \\
\hline Renklendirici & $\begin{array}{l}\text { Organik ve } \\
\text { inorganik } \\
\text { pigment }\end{array}$ & $\begin{array}{l}\text { Organik ve } \\
\text { inorganik } \\
\text { pigment }\end{array}$ & $\begin{array}{l}\text { Organik ve } \\
\text { inorganik } \\
\text { pigment }\end{array}$ \\
Bağlayıcı & Stirenakrilat & Nitroselüloz, & Fenolik ve \\
Madde & Solüsyon & Poliamid, & Hidrokarbon \\
& Emülsiyon vb. & Polivinilbutiral & reçineler \\
& & vb. & \\
Çözücü & Su & Isopropanol, & Mineral ve \\
Madde & Alkol & Etanol, Etilasetat, & Bitkisel \\
& Glikol vb. & Glikoleter gibi & yağlar (soya \\
& & solventler & yağı, keten \\
& & & yağı, bezir \\
& & Wă & Kurutucular \\
Katkı & Wax & Wlastikleştirici & Wax \\
Maddesi & Köpük Kırıcı & Çapraz bağlayıcı & Dolgu \\
& Çapraz & vb. & maddeleri \\
& bağlayıcı & & \\
& Dolgu & & \\
& Maddeleri & &
\end{tabular}

Mürekkeplerin bileşeninde yer alan VOC, toksik maddeler ve aşındırıcı maddeler belirli dozların üzerinde maruz kalındığında insan sağlığı ve çevre için zararlı maddeler haline gelmektedir. Bu durum 1996 yılında Uluslararası Kanser Araştırma Ajansının (IARC) baskı sürecinde kullanılan kimyasalların sağlık açısından olumsuz sonuçlar ürettiği ve muhtemelen kanserojen olduğu sonucuna varmasıyla resmiyet kazanmıştır [39-41]. Ayrıca VOC'a maruz kalma sonucu ortaya çıkan olumsuz sağlık etkilerinin görme bozukluğu, karaciğer yetmezliği, hiperglisemi ve bazı nörolojik semptomlarla yakın bir ilişkisi olduğunu gösteren çalışmalar ve böbrek, deri, mide kanseri gibi sağlık sorunlarını belirten raporlar vardır [42-46]. Bunun yanı sıra yanıcı ve parlayıcı özellikteki mürekkep bileşenleri, uygun koşullar altında oluşturabilecekleri alevlenme, patlama gibi durumlardan dolayı tehlikeli maddeler olarak mürekkep bileşeninde yer almaktadirlar. Yenilenebilir Kaynakların Mürekkep Üretiminde
Kullanımı İle İlgili Örnek Çalışmaların İncelenmesi Mürekkeplerin üretiminde yenilenebilir kaynaklara duyulan ihtiyaç doğrultusunda bitkisel yağ ve doğal reçineler kullanılarak çalışmalar yapıldığ görülmektedir. 1994 y1lında S.Z. Erhan ve M.O. Bagby "Polymerization of Vegetable Oils and Their Uses in Printing Inks" isimli çalışmalarında aspir, soya fasulyesi, ayçiçeği, pamuk tohumu ve kanola yağlarını sırasıyla mürekkep yapısında kullanarak bitkisel yağların polimerizasyonu ile baskı mürekkeplerindeki kullanımını incelemişılerdir [47]. Çalışmalarında ofset baskı tekniğinde suyun yağı itmesi prensibini koruması amacıyla yağların, yağ asitleri bakımından özelliklerini göz önünde bulundurmuşlar ve seçtikleri yağların mürekkebin hidrofobik yapısını korumasına dikkat etmişlerdir. Sonuç olarak kanola yağı dişındaki diğer bazı bitkisel yağların da mürekkep yapısında renk ve hidrofobik uyumluluklarının olduğunu tespit ederek bitkisel yağ bazlı ofset bask1 mürekkebinde kullanılabileceğini de görmüşlerdir. 1997 yılında P.Sabin, B. Benjelloun-Mlayah ve M. Delmas ayçiçek yağı ve kolza tohumu yağından ofset mürekkebinin reçine sentezini yaparak mürekkep yapısında bu yağların kullanılabilirliğini incelemişlerdir [48]. Ofset mürekkeplerinin reçinesinde genellikle yer alan keten tohumu yağı alkid reçineleriyle karşılaştırma yapmışlardır.

Çalışmanın neticesinde yağların ofset baskı mürekkeplerinin spesifik gereksinimlerini büyük ölçüde karşılayabildiğini gözlemlemişlerdir. A.S. Roy ve arkadaşları 2007 yılında kolza tohumu yağı, soya fasulyesi yağı, pirinç kepeği yağı ve palm yağını mürekkebin yapısında kullanarak; uçucu organik bileşiklerin kullanımını azaltmak ve yenilenebilir kaynakların kullanımını arttırabilmek amacıyla bitkisel yağ bazlı ofset mürekkebi geliştirmişlerdir [24]. Bitkisel yağlarla ofset baskı mürekkebi vernikleri hazırlayarak mürekkepleri formüllendirmişler, mürekkeplerin viskozite, densite, parlaklık, yapışkanlık ve sürtünme direnci gibi özelliklerine bakarak mineral yăg bazlı standart ofset baskı mürekkebiyle karşılaştırmışlardır. Karşılaştırma sonucunda bitkisel yağ bazlı 
mürekkeplerin mineral yă̆ bazlı mürekkeplere oranla baskı makinesinde çalışma stabilitesinin ve tabaka yüzeyi üzerinde görüntü kalitesinin iyi olduğu sonucuna ulaşmışlardır. Ayrıca çok az miktarda VOC içerdiği için bitkisel yă̆ bazlı mürekkeplerin çevre dostu yenilenebilir kaynaklar olduğunu vurgulamışlardır. Y. B. Ha ve arkadaşları fenol içermeyen çevre dostu mürekkep oluşturabilmek için doğal reçineleri sentezleyerek ofset mürekkebi yapısında kullanımını ve mürekkep özelliklerini (parlaklık, solma gibi) analiz etmişlerdir [49].

Analizler geleneksel reçinenin modifiye edilmiş fenol reçineye kıyasla parlaklık, sararma gibi özelliklerinin daha iyi olduğunu göstermiştir. J.M. Park, Y.H. Kim ve S.B. Kim'nin 2013 yılında doğal reçinelerle çözücüsüz ofset mürekkebi geliştirmek için beş farklı doğal reçine esteri kullanarak mürekkep formüle etmiş ve baskı kalitesindeki sonucunu incelemişlerdir [50]. Park ve arkadaşları soya yağını farklı moleküler ağırlığa ve çözünürlüğe sahip beş tip reçineye uygulamışlardır. Reçineler içerisinde daha büyük moleküler ağırlığa sahip olan yăg asidi esterlerinin basılabilirlik ve baskı kalitesi açısından daha iyi sonuç verdiğine ilişkin bulgular elde etmişlerdir. Tobias Robert 2014 yılında yenilenebilir kaynaklardan baskı mürekkebi üretimine ilişkin bir inceleme yaparak mürekkebin yapısındaki zararlı bileşenleri ve bunların yerine yenilenebilir kaynakların önemini anlatmıştır [1]. M. Biswas ve arkadaşları 2017 yılındaki çalışmalarında biyo bazlı (biobased) reçine sentezleyerek mürekkep yapısındaki VOC'u azaltmayı amaçlamışlardır [51]. Pentaeritritol yerine doğal bir polisakkarit olan Guar Gum kullanarak reçine sentezlemişler ve karşılaştırma yapabilmek amaciyla pentaeritritol içeren fenolik reçine de sentezlemişlerdir. Çalışma sonucunda Guar Gum ile daha yüksek molekül ağırlıklı ve yüksek çözücü tolerans değerine sahip reçine üretmeyi başarmışlardır. Çevre dostu Guar Gum içeren reçinenin potansiyel bağlayıcı olabileceğini ve standart reçinenin performansıyla eşleştiğini gözlemlemişlerdir. 2018 yılında C. Aydemir ve arkadaşları bitkisel ve mineral yağ bazlı mürekkeplerin kaplanmış ve kaplanmamış kağıt yüzeyi üzerindeki davranışlarını basılabilirlik açısından incelemişlerdir [23]. Soya yağı, keten tohumu yağı-soya yağı ve mineral yağ içeren üç farklı tip cyan renk mürekkebin numune kağıtlar üzerine baskısını yaparak numuneler üzerinde parlaklık, kontak açısı, yüzey enerjisi gibi ölçümlemelerini yapmışlardır. Kaplanmış ve kaplanmamış kağıt yüzeyleri üzerinde bitkisel ve mineral yă esaslı mürekkeplerin baskı kalitesi açısından benzer özellikler gösterdiğini tespit etmişlerdir. Yine 2018 yılında E. Ural ve arkadaşları Palm yağı katkılı mürekkeplerin baskı kalitesine etkisini inceleyerek mürekkep üretiminde palm yağının cold-set mürekkepler için mineral bazlı yağların yerine kullanılabileceğine ilişkin sonuçlar elde etmişlerdir [17].

\section{SONUÇ ve ÖNERİLER}

Literatür taramalarındaki çalışmalar göstermiştir ki; basım sektöründe temel hammaddelerden birisi olan ofset baskı mürekkebi bileşeninde yenilenebilir kaynakların kullanımına ilişkin olumlu sonuçlar bulunmaktadır. $\mathrm{Bu}$ durum, petrokimyasal maddeler içeren mürekkep formülasyonun yerini bitkisel bazlı ürünlere bırakmasında, önemli bir gösterge ve teşvik oluşturmaktadır. İnsan sağlı̆̆ sürdürülebilirliği düşünüldüğünde yenilenebilir kaynakların kullanımına ilişkin artan talebin her alanda olduğu gibi basım sektörü alanında da önemi büyüktür. $\mathrm{Bu}$ amaçla mürekkep bileşeninde yer alabilecek bitkisel kaynakların araştırılması ve hangilerinin kullanılabilir olabileceğinin belirlenmesi endüstriyel üretim için bilgi sağlamaktadır. Fakat henüz bu alanda yeterli bilgi oluşmamıştır ve araştırmalar genişletilebilecek kapsamdadır. Ülkemizde TÜİK 2019 verilerine göre sadece gazete ve dergilerin toplam bask1 sayıs 1.259.068.089'dir. Bu sayı diğer basılı ürünler ve dünya çapındaki basım sayısı olarak düşünüldügüunde ciddi bir hammadde giderini ifade etmektedir. Mürekkep gibi temel bir hammaddenin çevreci içerikli olması mürekkepten doğaya yayılan zararlı petrokimyasalların azalmasını sağlayacaktır. Bitkisel yağların, doğal reçinelerin, hatta atık maddelerin mürekkep bileşeninde yer alması ve basılabilirlik açısından yeni verilerin elde edilebilmesi çevreci mürekkep üretiminde önemli rol oynamaktadır. Bu bileşenlerin yer aldığı mürekkeplerin basım sektöründe kullanımı da çevre ve insan sağlı̆̆ açısından fayda sağlayacaktır.

\section{KAYNAKÇA}

[1] Robert T. Green ink in all colors-printing ink from renewable resources, Progress in Organic Coatings An International Journal, 78 287-292, 2014.

[2] Arslan Z.K. Keton/Aldehit reçinelerinin . mürekkep hazırlanmasında kullanımı, İstanbul Teknik Üniversitesi Fen Bilimleri Enstitüsü, Yüksek Lisans Tezi, s. 3, 2015.

[3] Ülgen M., Oktav M., Gencoğlu E.N. Matbaacının mürekkep hakkında bilmesi gerekenler, Basev Yayınları, Haziran 2012, s. 310, 2012.

[4] Erhan S.Z., Nelsen T.C. Comparisons of volatile organic chemical content of news, Sheetfed and Heatset Ink Formulations, JAOCS, 78 419-422, 2001.

[5] Ülgen M., Oktav M., Cakır N. Grafik sanatları için kimya, Basev, s. 379, 2019.

[6] Erhan S.Z., Bagby M.O. Lithographic and letterpress ink vehicles from vegetable oils, JAOCS, 68 635-638, 1991.

[7] Roy A.S., Bhattacharjee M., Mondal R., Ghosh S. Development of mineral oil free offset printing ink using vegetable oil esters. Journal of Oleo Science, 56 623-628, 2007.

[8] Yürekli Ş. Reçine ve boya teknolojisi, Cilt 1, Marshall Boya ve Vernik sanayii A.Ş. Yayını, s. 39, 1995.

[9] Jansen M., Letschert H.P. Inorganic yellow-red pigments without toxic metals, Macmillan Magazines, Letters to Nature. 404 980-982, 2000.

[10] Erhan S. Z., Bagby M.O. Polvmerization of vegetable oils and their uses in printing inks, Journal of The American Oil Chemists' Society, 71 1223-1226, 1994.

[11] Sabin P., Benielloun-Mlavah B., Delmas M. Offset printing inks based on rapeseed and sunflower oil. part I: synthesis and characterization of rapeseed oiland sunflower oil-modified alkyd resins, Journal of the American Oil Chemists' Society, 74 481- 489, 1997.

[12] Ha Y.B., Jin M.Y., Oh S.S., Ryu D.H. Synthesis of an environmentally friendly phenol-free resin for printing 
ink, Bulletin of The Korean Chemical Society, 33 34133416, 2012.

[13] Park J.M., Kim Y.H., Kim S.B. Development of solventfree offset ink using vegetable oil esters and high molecular-weight resin, Journal of Oleo Science, 62 345352, 2013.

[14] Phunphoem S., Saravari O., Supaphol P. Alkyd printing inks from waste frying oil, Walailak J Sci Tech, 17 811824, 2020.

[15] Chiplunkar P. P., Pratap A. P. Utilization of sunflower acid oil for synthesis of alkyd resin, Progress in Organic Coatings, 93 61-67, 2016.

[16] Daugherty J. A Realistic Appraisal of Soy Oil Printing Inks - 2007, Napim Bulletin, 07-15, s. 1-5, 2007.

[17] Wei W., Wang S., Hao J., Cheng S. Projection of anthropogenic volatile organic compounds (VOCs) emissions in China for the period 2010-2020, Atmospheric Environment, 45 6863-6871, 2011.

[18] Alabdulhadi A., Ramadan A., Devey P., Boggess M., Guest M. Inhalation exposure to volatile organic compoundsin the printing industry, Journal of the Air Waste Management Association, 69 1142-1169, 2019.

[19] Word health organization international agency for research on cancer. IARC monographson the evaluation of carcinogenic risks to humans, Printing pprocesses and printing inks, carbon black and sorne nitro compounds, $s$. 59, $1996 . \quad$ (https://monographs.iarc.fr/wpcontent/uploads/2018/06/mono65.pdf), erișim tarihi 15.09.2020

[20] Aksoy H., Yılmaz S., Celik M., Yüzbasıŏlu D., Ünal F. Genotoxicity study in lymphocytes of offset printingworkers, Journal of Applied Toxicology, 2610 15, 2006.

[21] Yenidoğan S., Matbaa mürekkeplerinde kullanılan renklendirici maddeler ve analizleri için kromatografik yöntemlerimn gelistirilmesi, Marmara Üniversitesi Fen Bilimleri Enstitüsü Matbaa Eğitimi Anabilim Dalı Doktora Tezi, İstanbul, s. 57. 2005.

[22] Porwal T. Paint pollution harmful effects on environment, Social Issues and Environmental Problems, $31-4,2015$.

[23] Dharavath HN, Hahn K. Green printing: colorimetric and densitometric analysis of solvent-based and vegetable oil-based inks of multicolor offset printing. J Tech Stud., 35 36-46, 2010.

[24] Chetehouna K. Volatile organic compounds: emission, pollution and control, New York: Nova Science Publishers, s. 169, 2014.

[25] Kalafatoğlu E., Örs N., Özdemir S.S. Uçucu organik bilesiklerin (VOC) teknoloiik ve ekonomik açidan optimum geri kazanılması ve/veva cevreve zararsiz duruma getirilmesi, Arıtım Dünyası, 18 37-50, 2000.

[26] Biswas M., Paul A., Dey M., Dey A., Bandyopadhyay A. Influence of a biobased reagent on properties of industrial resin for printing ink application vis-a-vis comparison with standard commercial resin, Polymers From Renewable Resources, 9 59-74, 2018.

[27] Kipphan H. Handbook of print media technologies and production methods, Springer-Verlag Berlin Heidelberg, Germany, s. 131, 2001.

[28] Roy A.S., Bhattachariee M., Mondal R., Ghosh S. Development of mineral oil free offset printing ink using vegetable oil esters, Journal of Oleo Science, 56 623-628, 2007.

[29] Bhattachariee M., Roy A.S., Ghosh S., Dey M. Development of karanja oil based offset printing ink in comparison with linseed oil, Journal of Oleo Science, 60 19-24, 2011.

[30] Yürekli S. Recine ve bova teknoloiisi, Cilt 2. Marshall Boya ve Vernik Sanayii A.Ş. Yayını, s. 88, 1997.

[31] Leach R.H., Armstrong C., Brown J.F., Mackenzie M.J. Randall L., Smith H.G. The printing ink manual, Van
Nostrand Reinhold (International) Co. Ltd., England, s. 1-192, 1988.

[32] Tanıstan B., Turan S. Fe-Cr siyah seramik pigment üretiminde ferrokrom kullanımı, Eskisehir Osmangazi Üniversitesi Mühendislik Mimarlık Fakültesi Dergisi, 2 $53-65,2010$.

[33] Leung M. K. H., Liu C. H., Chan A. H. S. Occupational exposure to volatile organic compounds and mitigation by push-pull local exhaust ventilation in printing plants, $\mathrm{J}$ Occup Health, 47 540-547, 2005.

[34] Diogo M., Kiurski J., Adamovi D., Miloradov M. V., Radonic J., Turk-Sekulic M. Hazardous air pollutants (HAPs) in printing facility in Novi Sad, International Journal Of Engineering, 9 101-104, 2011.

[35] Giod A., Netoa F. R. A. Exposure to high levels of volatile organic compounds and other pollutants in a printing facility in rio de janeiro Brazil, Indoor Built Environ, 11 302-311, 2002.

[36] Aydemir C.. Özakhun C. Matbaa malzeme bilimi, Marmara Üniversitesi Yayınevi, s. 225, 2014.

[37] Wadden R.A., Scheff P.A., Franks J.E., Conroy L.M. Determination of VOC emission rates and compositionsfor offset printing. Journal of the Air Waste Management Association, 45 547-555 1995.

[38] Report prepared in consultation with the NSW Environment Protection Authority (EPA) https://pdfs.semanticscholar.org/d2cd/5c09fcb042badb06 a31809dd299dc580f986.pdf, erișim tarihi: 07.09.2020.

[39] Godoi A.F.L., Sawada E.Y., Marchi M.R.R., Grieken R. V., Godoi R.H.M. Determination of BTEX by GC-MS in air of offset printing plants: comparison between conventional and ecological inks, Water Air Soil Pollut: Focus, 9 163-169, 2009.

[40] Rosli W.D.W., Kumar R.N., Zah S.M., Hilmi M.M. UV radiation curing of epoxidized palm oil-cycloaliphatic diepoxide system induced by cationic photoinitiators for surface coatings, European Polymer Journal, 39 593-600, 2003.

[41] Ural E., Özomav Z., Özdemir L. Palm vağ1 katkılı mürekkeplerin bask1 kalitesine etkisinin belirlenmesi, MSU Fen Bilimleri Dergisi, 6 534, 2018.

[42] Jelena K., Branislav M., Dragan A., Aleksandra M., Selena G., Ivana O., Jelena K. Register of hazardous materials in printing industry as a tool for sustainabledevelopment management, Renewable and Sustainable Energy Reviews, 16 660-667, 2012.

[43] Prica M., Kecić V., Adamović S., Radonić J., Turk Sekulić M. Occupational exposure to hazardous substances in printing industry, Proceedings of 8th International Engineering Symposium at Bánki. Proceedings of 8th International Engineering, Óbuda University, Budapest, Hungary, 1-8, 2016.

[44] Caselli M., Gennaro G., Saracino M.R., Tutino M. Indoor contaminants from newspapers: VOCs emissions in newspaper stands, Environmental Research, 109 149157,2009

[45] Tsai C.J., Mao I.F., Ting J.Y., Young C.H., Lin i. S., Li W.L. Ouality of chemical safety information in printing industry, Ann Occup Hyg., 60 361-370, 2015.

[46] Erhan S.Z., Bagby M.O. Vegetable-oil-based printing ink formulation and degradation. Industrial Crops and Products an International Journal, 3 237-246, 1995.

[47] Bartlett I. W., Dalton A. J. P., Mcguinness A., Palmer H. Substitution of organic solvent cleaning agents in the lithographic printing industry, The Annals of Occupational Hygiene, 43 83-90, 1999.

[48] USEPA. Initial List of Hazardous Air Pollutants with Modifications, United States Environmental Protection Agency, (https://www.epa.gov/haps/initial-listhazardous-air-pollutants-modifications), erișim tarihi 15.09.2020. 
[49] Aydemir C., Yenidoğan S., Karademir A., Kandırmaz E.A. The examination of vegetable and mineral oil based inks' effects on print quality: green printing effects with different oils, Journal of Applied Biomaterials Functional Materials, 1-7 137-143, 2018.

[50] Bruno P., Caselli M., Gennaro G., Iacobellis S., Tutino M. Monitoring of volatile organic compounds in nonresidential indoor environments, Indoor Air, 18 250-256, 2008.

[51] Morkbak A., Degn P., Zimmermann W. Deinking of soy bean oil based ink printed paper with lipasesand a neutral surfactan, Journal of Biotechnology, 67 229-236, 1999. 